\title{
Natural User Interfaces
}

\author{
António Câmara \\ YDreams - Informática S.A. \\ antonio.camara@ydreams.com \\ http: / /www.ydreams.com/
}

\begin{abstract}
Recent developments in user-input technologies are changing the way we interact with digital screens. The mouse and the keyboard are being replaced by touch and motion based interfaces, increasingly known as Natural User Interfaces (NUI). YDreams has developed Yvision, a platform that enables the development of natural user interfaces. YVision has a modular architecture matching YDreams technologies with the best of open source third party libraries. Our technologies emphasize the creation of smart interfaces using autonomous agents that go beyond the traditional reactive systems. Yvision also includes computer vision algorithms for motion detection and the application of 3D depth sensing in rendering engines. NUI applications involve: data acquisition using various sensors that detect the user's motion and gestures; interpretation of sensor data; and presentation, the end visualization layer. YVision includes augmented reality capabilities as a visualization component, where images are captured from the real world and enhanced in real-time with contextual information. Natural user interface applications, developed for both 2D and 3D depth sensing, will be presented for illustrative purposes. Applications include projects developed for clients such as Orange, Coca-Cola, Santander and Nike. Ongoing research projects focusing on digital signage and serious games will be also discussed.
\end{abstract}

\section{Short Biography}

António Câmara is Chief Executive Officer of YDreams and Professor at Universidade Nova de Lisboa. He got a BSc in Civil Engineering at IST (1977) and MSc (1979) and PhD (1982) in Environmental Systems Engineering at Virginia Tech. António Câmara was a Post-Doctoral Associate at Massachusetts Institute of Technology (MIT) and Visiting Professor at Cornell University (1988-89) and MIT (1998-99). António Câmara has been a pioneer on geographical information systems research. He published over 150 refereed papers and the "Spatial Multimedia and Virtual Reality" published by Taylor \& Francis (1999) and "Environmental Systems" published by Oxford University Press (2002). He is a founder of YDreams, a international leader in interactivity. YDreams has developed more than 600 projects in 25 countries for companies such as Nike, Adidas, Santander, Coca-Cola, NOKIA and Vodafone. The company has received over twenty awards including the Industrial Design Society of America Gold Award for Interactive Environments in 2004, and the Auggies, Augmented Reality's Oscar, in 2010. YDreams projects and products have been profiled in the New York Times, Guardian, Liberation, El Pais, Business Week, Economist, Wired, Engadaget, Gizmodo, CNN and CNBC. António Câmara has received several national and international awards, namely Premio Pessoa in 2006. 